- Communication-

\title{
Voltammetric Behavior of Cadmium(II) Iodide with a Hanging Mercury Drop Electrode Modified with Trioctylphosphine Oxide
}

\author{
Nakahide KATO and Takeshi HIDAK^
}

Received October 6, 1988 ; Accepted February 8, 1989

\section{Introduction}

Chemically modified electrodes with trioctylphosphine oxide (TOPO-modified electrode) can be easily prepared". This TOPO-modified electrode was applied to the uranyl ion system. Preconcentration of uranyl ion was observed in the TOPO layer. Subsequently, trace amounts of uranyl ion were determined by using the TOPOmodified electrode ${ }^{2,3)}$. H.owever, there was no detailed investigation except for the application of the TOPO-modified electrode to the uranyl ion system but some other metal ions were studied briefly ${ }^{4}$. Recently, the equilibria of $\mathrm{Cd}$ (II) halogeno complexes have been studied in solvent extraction systems of TOPO/hexane and the extraction constants of $\mathrm{Cd}$ ( II ) halogeno complexes were estimated ${ }^{5)}$. As the extraction constant of $\mathrm{Cd}$ ( II ) iodide was greater than those of chloro-and bromo-complexes, we now have dealt with the study on the electrochemical behavior of $\mathrm{Cd}$ ( II ) iodide preconcentrated on the TOPOmodified electrode. In this communication, application of a TOPO-modified hanging mercury drop electrode (HMDE) is described for the voltammetric measurements of $\mathrm{Cd}$ ( II ) iodide and ability of electroanalytical probe of $\mathrm{Cd}$ ( II ) ion.

\section{Experimental}

The TOPO was a Dotite reagent (Dojindo Co.). Other reagents used were of analytical reagent grade. The TOPO-modified electrode was prepared by immersing in a $5 \times 10^{-2} \mathrm{~mol} \mathrm{dm}^{-3} \mathrm{TOPO}$ ethanolic solution for a few seconds. A stock solution of $1.0 \times 10^{-3} \mathrm{~mol} \mathrm{dm}^{-3} \mathrm{Cd}$ ( II ) ion was prepared by dissolving pure cadmium metal in a

Department of Chemistry, College of Science, Rikkyo University (3-34 Nishi-Ikebukuro, Toshimoku, Tokyo, 171) Key Words: Cyclic Voltammetry, Cadmium (II) Iodide, Trioctylphosphine Oxide, Chemically Modified Electrode and Preconcentration small amount of concentrated nitric acid. As described by Lubert et $\mathrm{al}^{23}$., preconcentration of $\mathrm{Cd}$ (II) ion was carried out by immersing the TOPO-modified electrode in Cd ( II ) ion solution under open circuit.

Cyclic and differential pulse voltammograms were measured by using a polarograph model 312 (Fuso Seisakusho Co., Kawasaki) with a function generator HB-104 (Hokuto Denko Ltd., Tokyo). A hanging mercury electrode $(0.017$ $\mathrm{cm}^{2}$ ) was model AS-01 (Mitsubishi Chemical Industries Ltd., Kanagawa). All the potentials were referred to a saturated calomel electrode (SCE); and all the electrochemical measurements with the TOPO-modified electrode were carried out in a phosphate buffer solution containing $0.5 \mathrm{~mol} \mathrm{dm}^{-3}$ sodium sulfate as supporting electrolyte in a nitrogen atmosphere.

\section{Results and Discussion}

The TOPO-modified electrode was dipped for $30 \mathrm{~s}$ in a $10^{-5} \mathrm{~mol} \mathrm{dm}^{-3} \mathrm{Cd}$ ( II ) solution which was free from iodide ions. The cyclic voltammogram showed no wave corresponding to the reduction or oxidation of cadmium (curve $\mathrm{A}$ in Fig. 1), indicating that no $\mathrm{Cd}$ (II) ion was preconcentrated in the TOPO layer. When the TOPO-modified electrode was dipped in the $10^{-5}$ mol dm${ }^{-3} \mathrm{Cd}$ ( II ) solution containing $0.1 \mathrm{~mol}$ $\mathrm{dm}^{-3}$ iodide ion, the cyclic voltammogram showed two peaks, whose peak potentials for cathodic and anodic processes were $E_{\rho, c}=-0.65$ and $E_{p, a}=-0.58 \mathrm{~V}$, respectively (curve $\mathrm{B}$ of Fig. 1). This result showed that $\mathrm{Cd}$ ( II ) iodide was precon-centrated in the TOPO layer.

From the results of Fig.2, this electrode system is considered to take part in both the adsorption and diffusion in the cathodic and anodic processes. At multi-sweep cyclic voltam- 


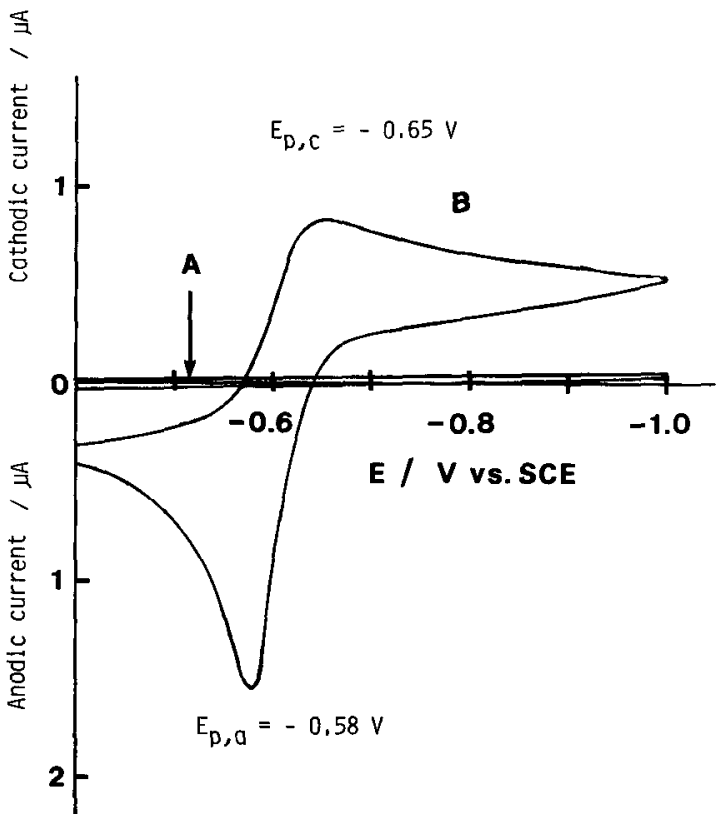

Fig. 1 Cyclic voltammograms of cadmium (II) with TOPO-modified electrode

Scan rate $: 0.1 \mathrm{~V} / \mathrm{s}$,

Curve A : iodide-free preconcentration solution

Curve B : $0.1 \mathrm{~mol} \mathrm{dm}^{-3}$ sodium iodide preconcentration solution

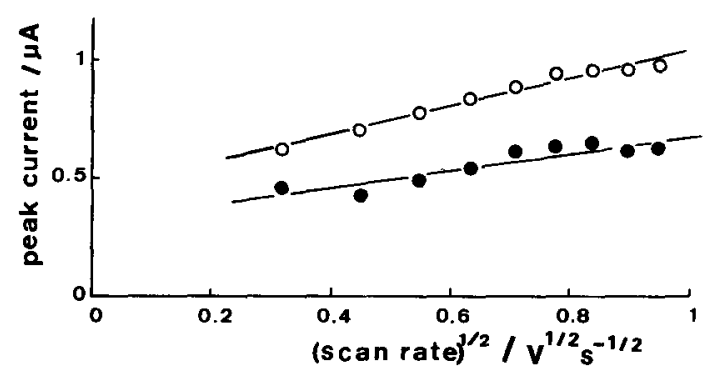

Fig. 2 The relation between (scan rate) $)^{1 / 2}$ and peak height of cyclic voltammograms

(O) : anodic peak height,

(C) : cathodic peak height

metry, cathodic and anodic peak heights obtained by repeating potential sweeps were kept constant by using a scan rate more than $100 \mathrm{mV} / \mathrm{s}$.

From the analytical aspect, differential pulse polarography was applied to the cadmium TOPO-

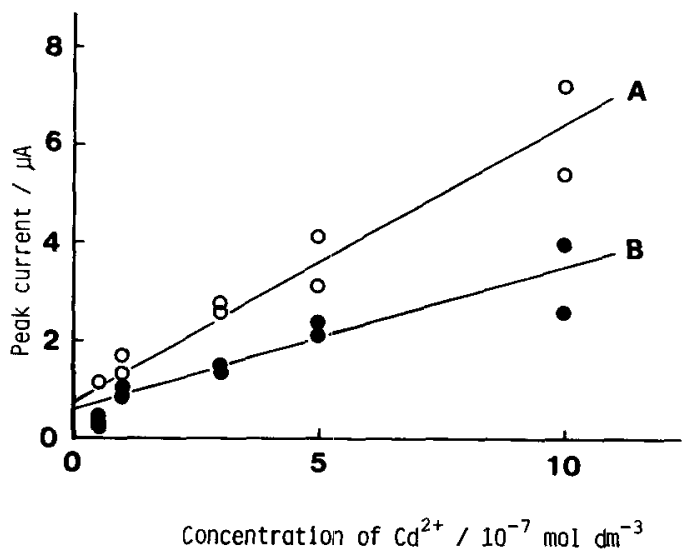

Fig. 3 The relation between concentration of $\mathrm{Cd}$ (II) and peak height of differential pulse polarograms Scan rate $: 0.02 \mathrm{~V} / \mathrm{s}$

Modulation amplitude : $20 \mathrm{mV}$,

Preconcentration time: $5 \mathrm{~min}$,

(O) : cathodic peak height,

(O) : anodic peak heitht

modified electrode system, because this technique provides much higher sensitivity than cyclic voltammetry and most suitable peak shapes for measuring signals ${ }^{6}$. The relationships between the concentration of $\mathrm{Cd}$ ( II ) ion $\left(10^{-6} \sim 5 \times 10^{-8}\right.$ mol $\mathrm{dm}^{-3}$ ) and the heights of cathodic and anodic peak were obtained as shown in Fig. 3. These two curves show linear relations, respectively as follows.

$$
\begin{gathered}
I_{p, a}(\mu A)=0.57 \times 10^{7}[\mathrm{Cd}(\text { II })]+0.76 \\
\quad(\text { curve A }) \\
I_{p, c}(\mu A)=0.29 \times 10^{7}[\mathrm{Cd}(\text { II })]+0.56 \\
\quad(\text { curve B })
\end{gathered}
$$

where [Cd (II )] represents the molar concentration of $\mathrm{Cd}$ ( II ) ion. It can be concluded that trace amounts of $\mathrm{Cd}$ ( II ) ion can be determined by using this preconcentration technique.

\section{References:}

1) K. Izutsu, T. Nakamura and T. Oku, Nippon Kagaku Kaishi, 1656 (1980).

2) K. H. Lubert, M. Schnurrbusch and A. Thomas, Anal. Chim. Acta, 144, 123 (1982).

3) K. Izutsu, T. Nakamura and T. Ando, Anal. Chim. Acta, 152, 285 (1983)

4) J. Lexa and K. Stulik, Talanta, 32, 1025 (1985).

5) S. Iwahori, R. Miura and R. Murai, Bunseki Kagaku, 34, 727 (1985).

6) A.M. Bond, "Modern polarographic methods in analytical chemistry", page 236-284, Marcell Dekker, Inc. New York, (1980). 